\title{
Caracterização Proposta para o Comitê de Auditoria no Código de Governança Corporativa do Brasil e de Outros Países
}

\begin{abstract}
Resumo
A governança corporativa deve zelar pela transparência das informações contábeis apresentadas ao público. Nesse sentido, os códigos de governança corporativa propõem a criação do conselho de administração e como suporte o comitê de auditoria. Este estudo objetiva comparar a caracterização proposta para o comitê de auditoria no código de governança corporativa do Brasil e de outros países. Pesquisa de natureza qualitativa foi realizada por meio de análise de conteúdo dos códigos de governança corporativa de 17 países que reportam características do comitê de auditoria. Analisou-se também a aplicação do que é proposto ao comitê de auditoria no Brasil pelo Instituto Brasileiro de Governança Corporativa (IBGC) em empresas catarinenses que possuem ações negociadas na Bovespa. Os resultados mostram semelhanças nos quesitos propostos ao comitê de auditoria entre os países analisados, particularmente na composição, qualificação dos membros e atribuições. No que concerne à implementação da proposição do comitê de auditoria em empresas catarinenses, observouse que a maioria apresenta um conselho fiscal em vez do comitê de auditoria. Conclui-se que, apesar das semelhanças na caracterização dos comitês de auditoria identificadas nos códigos de governança corporativa, ainda são necessárias pesquisas para criar um padrão que possa ser proposto pelos órgãos reguladores às empresas.
\end{abstract}

Palavras-chave: Governança corporativa. Conselho de administração. Comitê de auditoria.

\section{Ilse Maria Beuren \\ Doutora em Controladoria e Contabilidade (FEAUSP) e Professora da Universidade Federal do Paraná - UFPR. Contato: Av. Prefeito Lothário Meissner, 632, Campus III, Jardim Botânico, Curitiba, PR, CEP: 80210-070. \\ E-mail: ilse.beuren@gmail.com}

\section{Simone Nass}

Bacharel em Ciências Contábeis pela Universidade Regional de Blumenau FURB. Contato: Rua Antônio da Veiga, 140 , Victor Konder, Blumenau, SC, CEP: 89012-900.

E-mail: mony.sn@hotmail.com

\section{Viviane Theiss}

Mestre em Ciências Contábeis pela Universidade Regional de Blumenau FURB. Contato: Rua Antônio da Veiga, 140 , Victor Konder, Blumenau, SC, CEP: 89012-900.

E-mail: viviane_theiss@hotmail.com

\section{Paulo Roberto da Cunha}

Doutor em Ciências Contábeis e Administração (FURB) e Professor da Universidade Regional de Blumenau FURB. Contato: Rua Antônio da Veiga, 140, Victor Konder, Blumenau, SC, CEP: 89012-900.

E-mail: pauloccsa@furb.br 


\section{Introdução}

A Governança Corporativa tem motivado diversas pesquisas após vários escândalos de fraudes contábeis que abalaram o mercado financeiro nos Estados Unidos entre 2000 e 2002. Esse interesse ocorre pelo fato de a Governança Corporativa oferecer mecanismos que conseguem promover a minimização de riscos que possam afetar o retorno dos investimentos efetuados por diferentes investidores nas organizações.

Guerra (2009) aborda que os escândalos empresariais, especialmente nos Estados Unidos, na virada do século XXI, acentuaram a desconfiança e o conflito nas organizações. O histórico de fraudes das empresas Enron, WorldCom e Tyco foi o resultado de processos viciosos baseados em assimetria de informações, divergência de interesse e desacerto de propósitos, com doses de ganância e ausência de princípios básicos de conduta ética.

A partir das demonstrações contábeis divulgadas aos seus usuários internos e externos, a empresa busca agregar valor ao negócio, mas, para isso, precisa transmitir confiança aos seus usuários. Para obter maior confiança, lhe é exigido transparência. Nesse sentido, os códigos de governança corporativa propõem a criação do conselho de administração, que é recomendado para todas as empresas. Esse conselho pode criar comitês para cuidar de assuntos específicos, como o comitê de recursos humanos, o comitê de auditoria ou outro que julgar necessário.

Silva (2006) expõe que o conselho de administração deve estimular a instituição do comitê de auditoria para analisar as demonstrações contábeis; promover a supervisão e a responsabilização da área contábil; garantir que a diretoria desenvolva controles internos confiáveis; assegurar que a auditoria interna desempenhe a contento o seu papel; e que os auditores independentes avaliem, por meio de sua própria revisão, as práticas da diretoria e da auditoria interna. O comitê de auditoria deve ainda zelar pelo cumprimento do código de conduta da organização, sendo uma importante fonte de controle dentro das organizações.

Os comitês dentro da governança corporativa têm a finalidade de aumentar a eficiência do conselho de administração e supervisionar situações mais complexas que exigem suporte específico. O comitê de auditoria é um dos comitês que o conselho pode instituir para lidar com assuntos de contabilidade e gerenciamento de riscos da empresa, visto que o comitê de auditoria é um dos componentes da governança (Silva, 2006).

Fundamentado nesse entendimento, diversos códigos de boas práticas de governança corporativa no mundo têm incentivado e orientado a constituição e a manutenção desse órgão no intuito de contribuir no processo de governança das empresas. Nesses códigos, como também em pesquisas na área, diversos aspectos e características do comitê de auditoria são apresentados e discutidos, como sua composição (Vicknair, Hickman, \& Carnes, 1993; DeZoort, Hermanson, Archmbeault, \& Scoot, 2002; Bronson, Carcello, Hollingsworth, \& Neal, 2009), qualificação (Dezoort, \& Salterio, 2001; IBGC, 2009), mandato (IBGC, 2009) e atribuições (Carcello, Hermanson, \& Neal, 2002).

Com base no exposto, elaborou-se a seguinte questão de pesquisa: Quais são as semelhanças e diferenças nas características de composição, qualificação, mandato e atribuições do comitê de auditoria propostas no código de governança corporativa do Brasil e de outros países? Assim, o estudo objetiva comparar a caracterização proposta para o comitê de auditoria no código de governança corporativa do Brasil e de outros países. A relevância da pesquisa está na análise de uma possível convergência na caracterização do comitê de auditoria em âmbito mundial, o que favoreceria o comparativo da governança das empresas, além de inspirar maior confiança nas informações contábeis apresentadas ao público.

O comitê de auditoria desempenha importante papel para o conselho de administração das empresas, principalmente pelo seu foco e envolvimento no processo e elaboração das demonstrações financeiras. Ter características desse órgão alinhadas em diferentes países pode contribuir não somente às empresas, mas em especial ao mercado de capitais. No entanto, chama atenção uma pesquisa realizada pela PricewaterhouseCoopers (2007) com companhias listadas na BM\&FBovespa, em que foi constatada a inexistência deste órgão em 54\% das empresas listadas no Novo Mercado e 31\% nas companhia listadas no Nível 2. 
Desse modo, o estudo justifica-se em termos práticos pelos seguintes motivos: para as empresas que ainda não possuem o comitê de auditoria vejam sua importância na organização; para as que o possuem, que analisem se ele atende ao que é proposto pelo código de governança corporativa no Brasil; para os órgãos reguladores, que comparem o que é proposto pelo IBGC, com o código de outros países, para criar um padrão mundial; para o mercado de capitais, com a adoção de um padrão único de composição, qualificação, mandato e atribuições do comitê de auditoria, o que facilita o entendimento dos usuários e confere maior transparência às informações, que é uma das formas de adicionar valor à empresa.

\section{Governança Corporativa e Comitê de Auditoria}

A governança corporativa se tornou elemento importante nas organizações, principalmente nas que possuem ações negociadas em bolsas de valores pelo mundo. É uma forma de controle criada para evitar possíveis fraudes, além de ser um código de conduta dentro da empresa. Embora tenha se tornado um assunto que veio à tona, recentemente, devido a grandes escândalos ocorridos em empresas, há algum tempo já era abordado. Cipullo (2006, p. 5) ressalta que escândalos corporativos ocorridos no mundo "forçaram muitas empresas a constituir o seu comitê de auditoria" como forma de imprimir maior transparência e confiabilidade aos negócios e, consequentemente, aos relatórios contábeis.

Ainda como decorrência dos diversos escândalos financeiros ocorridos no período de 2000 a 2002, como o caso da Xerox, Delphi Corporation, Global Crossing, WorldCom e Enron, destaca-se a instalação de uma crise no mercado de capitais norte-americano, que culminou na promulgação da Lei Sarbanes-Oxley (SOX), em julho de 2002, nos Estados Unidos. Essa Lei estabeleceu diversas mudanças na governança corporativa e nos relatórios financeiros das empresas, na tentativa de recuperar a confiança dos investidores no mercado de capitais (Engel, Hayes, \& Wang, 2007). Entre os diversos aspectos tratados nessa Lei, a seção 205 prevê o comitê de auditoria como um órgão estabelecido por e entre o conselho de administração, com a finalidade de supervisão da Contabilidade e dos relatórios financeiros.

Em paralelo e na mesma direção, com vistas a aprimorar o monitoramento dos relatórios financeiros por meio da SOX, foi criada em 2002 The Public Company Accounting Oversight Board (PCAOB), uma organização sem fins lucrativos norte-americana com a finalidade de supervisionar as empresas de auditoria, com o objetivo de proteger os interesses do público interessado e dos investidores a partir das opiniões descritas nos relatórios de auditoria (PCAOB, 2013).

A auditoria independente é um agente de governança corporativa de importância para todas as partes interessadas, uma vez que sua atribuição básica é verificar se as demonstrações contábeis refletem, adequadamente, a realidade da sociedade. Apesar da sua independência na análise e emissão do parecer, não é suficiente para assegurar que durante o processo de governança ocorra a transparência desejada. Os comitês internos devem auxiliar o conselho de administração e a diretoria executiva na transparência, confiabilidade e efetividade do desempenho de suas funções e responsabilidades.

Os comitês de auditoria desempenham papel importante na supervisão e acompanhamento do processo de informação financeira, dos controles internos e da auditoria externa (Sharma, Naiker, \& Lee, 2009). O comitê de auditoria é um comitê do conselho de administração, responsável pelos relatórios financeiros, que envolve a supervisão das escolhas das políticas contábeis, a contratação da auditoria externa e da supervisão do processo de auditoria e de monitoramento do controle interno (Chan, Liu \& Sun, 2012).

Furuta (2010) comenta que, apesar da expectativa de que o comitê de auditoria possibilite uma maior transparência nas atividades sociais da empresa, os órgãos reguladores e governamentais, além de pesquisadores de vários países, têm questionado sobre a efetividade do comitê de auditoria e sua contribuição para a governança corporativa. Pois, em algumas empresas que possuíam membros altamente qualificados, estes não foram capazes de identificar irregularidades dentro da organização.

Niyama (2005) menciona que o sistema legal de um país pode influenciar o seu comportamento e o direcionamento em relação à profissão contábil e ao financial reporting. Explica que os posicionamen- 
tos classificam-se em duas correntes: (i) Common-law - é predominante em países como Grã-Bretanha, Estados Unidos, Canadá, Austrália e Nova Zelândia, onde não se faz necessário detalhar as regras a serem aplicadas para todos os casos ou para todas as situações; e (ii) Code-law - predominante em países como Alemanha, França e Japão, que tem uma estrutura legal em que é requerido um elevado grau de detalhamento das regras a serem cumpridas, incluindo procedimentos a serem observados pelas empresas.

Diversas pesquisas sobre governança corporativa ressaltam diferentes aspectos relacionados ao comitê de auditoria. Mas nesta pesquisa, em consonância com o objetivo estabelecido no estudo, aborda-se em específico a composição (Vicknair, Hickman, \& Carnes, 1993; DeZoort, Hermanson, Archmbeault, \& Scoot, 2002; Bronson, Carcello, Hollingsworth, \& Neal, 2009; Chatterjee, 2011), a qualificação dos membros do comitê (DeZoort, \& Salterio, 2001; McDaniel, Martin, Maines, \& Peecher, 2002; IBGC, 2009; Mustafa, \& Youssef, 2010), o mandato (IBGC, 2009) e as atribuições (Carcello, Hermanson, \& Neal, 2002).

Quanto à composição, o IBGC (2007) destaca que é desejável que o comitê de auditoria seja composto totalmente por membros independentes. Já em alguns países, conforme PricewaterhouseCoopers (2007, p. 41), é requerido que todos os membros sejam não executivos e independentes, pois membros independentes têm mais facilidade para expressar suas opiniões de maneira livre e irrestrita.

Bronson, Carcello, Hollingsworth, \& Neal (2009) analisaram se a composição de um comitê de auditoria totalmente independente é necessária para a obtenção de resultados eficazes de monitoramento, frente ao debate de amenizar as exigências da Lei Sarbanes-Oxley (SOX) para empresas pequenas e estrangeiras. Os resultados sugerem que os benefícios da independência dos membros do comitê de auditoria são alcançados somente quando esse órgão é completamente independente. Esses resultados fornecem suporte para a exigência da SOX, de que os comitês de auditoria devem ser compostos somente por membros independentes. $\mathrm{O}$ comitê de auditoria deve ter no mínimo três membros independentes e que no mínimo um com conhecimentos em contabilidade e finanças (Chatterjee, 2011).

A relação entre a independência do comitê de auditoria e os relatórios da auditoria foi examinada por Carcello e Neal (2000). Analisaram empresas que enfrentaram dificuldades financeiras, considerando-se a relação entre o percentual de membros independentes no comitê de auditoria e a probabilidade de emissão de um relatório de continuidade das operações da empresa. Para as empresas com maiores dificuldades financeiras e com a maioria dos membros do comitê de auditoria não independentes, não houve apoio dos membros do comitê de auditoria sobre o tipo do relatório de auditoria emitido.

Outro aspecto sobre o comitê de auditoria, tratado no Blue Ribbon Committee (1999), é a qualificação dos membros. O documento destaca que, pelo fato de o comitê de auditoria ter como responsabilidade a supervisão da contabilidade societária e relatórios e controles financeiros, essa comissão tem nitidamente a necessidade de ter membros com conhecimento em contabilidade e/ou expertise financeiro.

A qualificação dos membros do comitê de auditoria é configurada nesta pesquisa como formação ou experiência na área financeira e de auditoria. DeZoort e Salterio (2001) investigaram se a experiência dos membros do comitê de auditoria e o conhecimento em demonstrações financeiras afetam suas decisões em situações de conflito entre o auditor independente e a gestão. Verificaram como 68 membros canadenses de comitês de auditoria reagem em casos de divergências entre o auditor e os gestores sobre um problema envolvendo escolhas e políticas contábeis. Constataram que um Comitê de Auditoria com membros independentes e conhecimento de relatórios de auditoria foi associado positivamente ao apoio do auditor em uma disputa entre auditor e gestores.

McDaniel, Martin, Maines e Peecher (2002) investigaram a qualidade das demonstrações financeiras de empresas com membros de comitês de auditoria com expertise financeira em comparação aos membros que foram alfabetizados financeiramente. Mustafa e Youssef (2010) investigaram a relação entre comitê de auditoria composto por membros qualificados (com expertise) e incidência de desapropriação de ativos em empresas norte-americanas. Os resultados demonstraram que um comitê de auditoria com membros independentes reduz a desapropriação de ativos se estes forem também qualificados. 
No que concerne às atribuições, Carcello, Hermanson e Neal (2002) analisaram o conteúdo de 150 relatórios que descrevem as atividades executadas pelo comitê de auditoria. O principal objetivo foi entender as atividades do comitê de auditoria e identificar possíveis áreas de melhorias do comitê. Constataram alta conformidade entre o que é obrigatório nas funções do comitê de auditoria com o que é divulgado em seus relatórios, como informações relacionadas à revisão e à discussão das demonstrações financeiras com a gestão. No entanto, a divulgação voluntária de atividades do comitê de auditoria foi mais comum para instituições financeiras, grandes empresas, companhias listadas na New York Stock Exchange (NYSE) e empresas com maior número de membros independentes no comitê.

A composição do comitê de auditoria, a qualificação dos membros, o mandato e as atribuições são elementos contemplados nos códigos de governança corporativa dos países. No Brasil, o IBGC (2007) propõe a criação do conselho de administração em todas as empresas e que este crie comitês para cuidar de assuntos específicos. No caso, o conselho de administração poderia criar o comitê de auditoria para cuidar de assuntos de contabilidade e gerenciamento de riscos da empresa. A caracterização desejável desse comitê é contemplada pelo IBGC (2009), mas as pesquisas apontadas, realizadas em âmbito internacional, instigam a investigação do que é o proposto nos códigos de governança de outros países.

\section{Método e Procedimentos da Pesquisa}

Esta pesquisa caracteriza-se como descritiva, que, de acordo com Gil (2002, p. 42), "tem como objetivo primordial a descrição das características de determinada população ou fenômeno ou, então, o estabelecimento de relações entre variáveis". Neste estudo, descreve-se a caracterização dos comitês de auditoria no código de governança corporativa do Brasil e outros países, analisando semelhanças e diferenças, além de cotejar as características do comitê de auditoria em empresas catarinenses com o proposto pelo IBGC (2009).

Quanto aos procedimentos, a pesquisa se caracteriza como documental, na qual conforme Lakatos e Marconi (2001, p. 174), "a fonte de coleta de dados está restrita a documentos escritos ou não". Neste estudo, a pesquisa documental pautou-se nos códigos de governança corporativa de diversos países, obtidos de sites da internet. Para analisar a implementação do comitê de auditoria, de acordo com a proposição do IBGC (2009) em empresas catarinenses, consultaram-se os seus arquivos sobre governança corporativa disponibilizados no site da Bolsa de Valores de São Paulo (Bovespa).

No que concerne à abordagem do problema, utilizou-se como estratégia a abordagem qualitativa, que, segundo Richardson (1989), é aquela que descreve a complexidade de determinado problema e analisa a influência mútua de certas variáveis, além de compreender e classificar processos dinâmicos vividos por grupos sociais. Nesta pesquisa, busca-se descrever de forma qualitativa: (i) o conteúdo dos códigos de governança corporativa do Brasil e de outros países; (ii) a caracterização proposta para o comitê de auditoria no código de governança corporativa do Brasil e de outros países; (iii) as semelhanças e diferenças propostas para o comitê de auditoria desses países.

A amostra compreendeu 17 países, incluindo o Brasil. A seleção dos países ocorreu, tendo como primeiro passo buscar os códigos de governança corporativa dos países mais desenvolvidos no mundo, no caso o grupo dos G8, que são: Estados Unidos, Japão, Alemanha, Inglaterra, França, Itália, Canadá e Rússia. Em seguida, os códigos dos demais países que adotam ou terão que adotar os International Financial Reporting Standards (IFRS). Por último, estão outros dois países que disponibilizaram seu código de governança corporativa em site eletrônico. Portanto, dessas três categorias de países, a amostra ficou restrita aos códigos de governança corporativa que se conseguiu acesso por meio eletrônico. Portanto, trata-se de uma amostra não probabilística, selecionada por conveniência.

Na Figura 1, constam os países que compõem a amostra da pesquisa, seu código de governança corporativa e o site em que se teve acesso aos dados coletados relativos à amostra. 


\begin{tabular}{|c|c|c|}
\hline País & Título do Código & Endereço eletrônico \\
\hline Alemanha & $\begin{array}{l}\text { German Code of Corporate Governance: Rules } \\
\text { for German Quoted Companies. }\end{array}$ & http://www.ecgi.org/codes/documents/code0700e.pdf \\
\hline Argentina & $\begin{array}{l}\text { Código de Mejores Prácticas de Gobierno } \\
\text { de lãs Organizaciones para la República } \\
\text { Argentina }\end{array}$ & $\begin{array}{l}\text { http://www.ecgi.org/codes/documents/argentina_2004_ } \\
\text { es.pdf }\end{array}$ \\
\hline $\begin{array}{l}\text { Arábia } \\
\text { Saudita }\end{array}$ & $\begin{array}{l}\text { Corporate Governance Regulations in the } \\
\text { Kingdom of Saudi Arabia }\end{array}$ & $\begin{array}{l}\text { http://www.ecgi.org/codes/documents/cg_regulations_ } \\
\text { saudi_arabia_16mar2012_en.pdf }\end{array}$ \\
\hline Áustria & Austrian Code of Corporate Governance & $\begin{array}{l}\text { http://www.ecgi.org/codes/documents/cg_code_austria_ } \\
\text { jan2012_en.pdf }\end{array}$ \\
\hline Brasil & $\begin{array}{l}\text { Código de Melhores Práticas de Governança } \\
\text { Corporativa do IBGC }\end{array}$ & $\begin{array}{l}\text { http://www.ecgi.org/codes/documents/ibcg_sep2009_ } \\
\text { pt.pdf }\end{array}$ \\
\hline Canadá & The Toronto Report on Corporate Governance & http://www.ecgi.org/codes/documents/tsx_gtgd.pdf \\
\hline Chile & $\begin{array}{l}\text { Potenciando El Gobierno Corporativo de lãs } \\
\text { Empresas em Chile. }\end{array}$ & $\begin{array}{l}\text { http://www.sbif.cl/sbifweb/servlet/ } \\
\text { Ebook?CTR=XXXXXXXXXXXXXXX\&ID_ } \\
\text { EBOOK=L3062\&position=0. }\end{array}$ \\
\hline China & $\begin{array}{l}\text { Provisional Code of Corporate Governance for } \\
\text { Securities Companies }\end{array}$ & $\begin{array}{l}\text { http://www.ecgi.org/codes/documents/provisional_ } \\
\text { cgcode_csrc.pdf }\end{array}$ \\
\hline Costa Rica & $\begin{array}{l}\text { Código Voluntario de Mejores Práctivas de } \\
\text { Gobierno Corporativo }\end{array}$ & $\begin{array}{l}\text { http://www.supervalores.gob.pa/files/Gobierno_ } \\
\text { Corporativo/Codigo_de_Gobierno_Corporativo_de_CR.pdf }\end{array}$ \\
\hline $\begin{array}{l}\text { Estados } \\
\text { Unidos }\end{array}$ & $\begin{array}{l}\text { Principles of Corporate Governance: Analysis } \\
\text { \& Recommendations }\end{array}$ & http://www.ecgi.org/codes/documents/brt_may2002.pdf \\
\hline França & Recommendations on Corporate Governance & $\begin{array}{l}\text { http://www.ecgi.org/codes/documents/afg_rec_jan2010_ } \\
\text { en.pdf }\end{array}$ \\
\hline Holanda & $\begin{array}{l}\text { Peters Report \& Recommendations: Corporate } \\
\text { Governance in Netherlands }\end{array}$ & $\begin{array}{l}\text { http://www.ecgi.org/codes/documents/nl-peters_report. } \\
\text { pdf }\end{array}$ \\
\hline Indonésia & Code for Good Corporate Governance & $\begin{array}{l}\text { http://www.ecgi.org/codes/documents/indonesia_ } \\
\text { cg_2006_en.pdf }\end{array}$ \\
\hline Inglaterra & The UK Corporate Governance Code & $\begin{array}{l}\text { http://www.ecgi.org/codes/documents/cg_code_uk_ } \\
\text { sep2012_en.pdf }\end{array}$ \\
\hline Malásia & Malaysian Code on Corporate Governance & $\begin{array}{l}\text { http://www.ecgi.org/codes/documents/malaysian_cg_ } \\
\text { code_mar2012_en.pdf }\end{array}$ \\
\hline México & Código de Mejores Prácticas Corporativas & $\begin{array}{l}\text { http://www.ecgi.org/codes/documents/codigo_de_ } \\
\text { mejores_practicas_corporativas_2010_es.pdf }\end{array}$ \\
\hline Singapura & Code of Corporate Governance & $\begin{array}{l}\text { http://www.ecgi.org/codes/documents/cg_code_ } \\
\text { singapore_2may2012_en.pdf }\end{array}$ \\
\hline
\end{tabular}

Figura 1. Código de governança corporativa dos países da amostra da pesquisa

Fonte: Endereços eletrônicos obtidos no site do European Corporate Governance Institute (ECGI). Index of codes. Disponível em: <http://www.ecgi.org/codes/ all_codes.php>. Acesso em: 03 jan. 2013.

Nos endereços eletrônicos descritos na Figura 1, coletaram-se os códigos de governança corporativa dos países que constituem a amostra da pesquisa, para fins de análise do conteúdo relativo à caracterização dos seus comitês de auditoria. Esses dados foram organizados em planilhas, tendo como referência as características propostas pelo IBGC (2009b) para o comitê de auditoria em empresas brasileiras, para posterior análise das semelhanças e diferenças constadas nos códigos de governança corporativa dos outros países.

Em relação à amostra de empresas para verificar a implementação no Brasil do comitê de auditoria de acordo com a proposição do IBGC (2009), utilizou-se como primeiro critério empresas com ações negociadas na Bovespa e, para restringir mais a pesquisa, já que não é este o objetivo geral do estudo, focalizaram-se empresas catarinenses que disponibilizaram arquivo sobre governança corporativa no site da Bovespa. Assim foram selecionadas 12 empresas para esse propósito adjacente da pesquisa. O propósito da seleção de empresas do Estado de Santa Catarina era a facilidade de acesso, caso fossem necessários esclarecimentos além dos divulgados ao público externo das empresas. 


\section{Descrição e Análise dos Dados}

Esta sessão apresenta inicialmente o conteúdo dos códigos de governança corporativa do Brasil e de outros países relativo às características propostas ao comitê de auditoria. Na sequência, apontam-se as semelhanças e diferenças constatadas entre os países relativamente ao proposto para o comitê de auditoria no Brasil. Por fim, com base nessas características identificadas, analisa-se a implementação do comitê de auditoria em empresas catarinenses com ações negociadas na Bovespa.

\subsection{Caracterização do Comitê de Auditoria no Brasil}

No Brasil, o IBGC (2007) recomenda que o comitê de auditoria seja formado por membros do conselho de administração, preferencialmente independentes, e composto de, no mínimo, três membros, todos com conhecimentos básicos de finanças e contabilidade. Pelo menos um deles deverá ter maior experiência na área contábil, de auditoria e de gestão financeira. Seu mandato pode ser limitado por meio do rodízio automático e/ou pela restrição do número de comitês a que um membro pode servir em outras empresas.

Entre as funções propostas ao comitê de auditoria, pode-se destacar: analisar as demonstrações contábeis; promover a supervisão e a responsabilização da área financeira; e garantir que a diretoria desenvolva controles internos confiáveis, que a auditoria interna desempenhe a contento o seu papel e que os auditores independentes avaliem, por meio de sua própria revisão, as práticas da diretoria e da auditoria interna (IBGC, 2007). O comitê deve ainda zelar pelo cumprimento do código de conduta da organização.

O comitê de auditoria deve reunir-se regularmente com o conselho de administração, o conselho fiscal, o executivo principal (Chief Executive Officer - CEO) e os demais diretores da companhia, para apresentar os relatórios financeiros e outros assuntos de interesse. Deve ainda assegurar-se quanto à qualidade das informações oriundas de controladas e coligadas, ou de terceiros (como peritos), considerando o reflexo dessas informações nas demonstrações contábeis da investidora (IBGC, 2007).

Em relação à adoção do conselho fiscal no lugar do comitê de auditoria nas empresas, o IBGC (2007) informa que o conselho fiscal não substitui o comitê de auditoria, uma vez que as funções de ambos são distintas. Ressalta-se, no entanto, que a proposição do Instituto Brasileiro de Governança Corporativa não se configura como uma normativa a ser obedecida pelas empresas, por isso é possível que a prática das empresas possa ser distinta da recomendação aqui apresentada.

\subsection{Caracterização do Comitê de Auditoria em Outros Países}

$\mathrm{Na}$ análise do conteúdo dos códigos de governança corporativa dos países pesquisados - Alemanha, Argentina, Arábia Saudita, Áustria, Canadá, Chile, China, Costa Rica, Estados Unidos, França, Holanda, Indonésia, Inglaterra, Malásia, México e Singapura -, identificaram-se as recomendações que seguem para a caracterização do comitê de auditoria.

$\mathrm{Na}$ Alemanha, o presidente do comitê de auditoria não deve ser um ex-membro do conselho administrativo da companhia, cujo mandato tenha encerrado em período inferior a dois anos. O comitê deve ser composto por pessoas com conhecimentos em contabilidade e finanças, e o presidente do comitê de auditoria deverá ter conhecimento e experiência na aplicação dos princípios contábeis e controle interno. Suas atribuições são lidar com questões de contabilidade, gestão de riscos e conformidade, independência exigida para o auditor e gestão do mandato da auditoria externa.

O comitê de auditoria na Argentina deve ser composto pelo menos por três diretores. Cada membro deve demonstrar conhecimento suficiente e experiência em contabilidade e nas questões de auditoria, finanças e gestão de riscos. O comitê deve monitorar: a integridade e a exatidão das demonstrações contábeis e de todas as informações de natureza contábil para fins de divulgação externa; cumprimento das 
leis e regulamentos; adequação e independência do auditor externo; desempenho do papel da auditoria interna e externa; e operações do sistema de controle interno. Ainda deve apresentar relatórios periódicos ao conselho sobre as medidas tomadas e os problemas discutidos em suas reuniões.

$\mathrm{Na}$ Arábia Saudita, a assembleia geral dos acionistas deve, sob a recomendação do conselho de administração, expedir regras de nomeação dos membros do comitê de auditoria e definir a duração do seu mandato e procedimentos a serem seguidos pelo comitê. A quantidade de membros não pode ser inferior a três, e executivos membros do conselho não podem ser eleitos para compor o comitê de auditoria. Entre seus membros, deve ter um especialista em assuntos contábeis e financeiros. São responsabilidades do comitê de auditoria: (i) supervisionar o departamento de auditoria interna para assegurar a sua eficácia na execução das atividades e obrigações especificadas pelo conselho de administração; (ii) analisar o processo de auditoria interna e preparar um relatório sobre a auditoria e as suas recomendações com relação a isso; (iii) rever os relatórios de auditoria interna e implementar medidas corretivas em relação aos comentários neles incluídos; e (iv) recomendar ao conselho de administração a nomeação e a remuneração dos auditores externos.

O comitê de auditoria na Áustria é responsável pelo acompanhamento dos preparativos para os procedimentos contábeis, acompanhamento do trabalho do auditor, da auditoria e da preparação e confirmação das demonstrações contábeis. Além disso, o comitê deve controlar a eficácia do sistema de controle interno e do sistema de gestão de risco da empresa. Pelo menos um membro do comitê deve possuir conhecimento específico que satisfaça às exigências da empresa e experiência prática na área. O presidente do comitê não pode ser uma pessoa que nos últimos três anos tenha atuado como membro do conselho de administração, em comitê de gestão de pessoas, como auditor da sociedade, ou que tenha assinado o parecer de auditoria, ou por qualquer outro motivo não seja independente.

No Canadá, o comitê de auditoria deve ser composto por pelo menos três diretores, os quais devem ser independentes financeiramente e possuir conhecimento financeiro e contábil. Entre suas atribuições estão: a nomeação dos auditores externos; supervisionar o trabalho dos auditores externos, incluindo a resolução de divergências entre a administração e os auditores externos; estabelecer procedimentos para lidar com reclamações no que diz respeito à contabilidade ou auditoria; e supervisão de auditores externos.

O comitê de auditoria no Chile tem como finalidade garantir que as informações contábeis publicadas pela companhia sejam completas, precisas, relevantes e oportunas. A atribuição do comitê de auditoria é discutir com os auditores externos os eventos mais relevantes ocorridos nos anos auditados. A empresa também precisa definir e informar ao público a política de rotatividade da empresa de auditoria.

$\mathrm{Na}$ China, o comitê de auditoria deve ser composto, exclusivamente, por conselheiros e presidido por um diretor independente, que precisa ser um profissional da Contabilidade. As principais funções do comitê são: recomendar a contratação ou substituição da empresa de auditoria externa; revisar o sistema de auditoria interna e sua execução; inspecionar as informações contábeis da empresa e sua divulgação; e monitorar o sistema de controle interno. Todas as propostas do comitê de auditoria devem ser apresentadas ao conselho de administração para revisão e aprovação. Cada comitê especializado será responsável perante o conselho de administração.

$\mathrm{Na}$ Costa Rica, o comitê de auditoria deve ser, preferencialmente, composto por diretores independentes. As funções do comitê de auditoria devem ser escritas de forma clara e publicadas no site da empresa. Entre as funções do comitê estão: (i) promover a responsabilidade e fiscalização da área financeira e garantir que a equipe executiva desenvolva controles internos confiáveis; (ii) elaborar relatórios periódicos ao conselho sobre suas ações; (iii) assegurar que os auditores externos possuam independência necessária para atuar com objetividade e eficiência; e (iv) assegurar que as recomendações e avaliações dos auditores externos foram abordados, no sentido de que a apresentação das informações contábeis sejam consistentes com eles. Recomenda ainda que o comitê de auditoria discuta com os auditores externos questões, como mudanças na aplicação dos princípios contábeis; utilização de reservas e provisões; questões relevantes utilizadas na preparação de relatórios contábeis; mudanças no âmbito da auditoria na identificação de áreas de alto risco; insuficiências e lacunas significativas nos controles internos; fatores externos (econômicos, regulatórios setoriais, etc.) que afetam os relatórios contábeis e de auditoria. 
O comitê de auditoria nos Estados Unidos geralmente é constituído de três a cinco membros e, pelo menos, um deve ter conhecimento em contabilidade financeira ou gestão. O comitê é responsável pela supervisão do processo de informação financeira da empresa e deve entender e estar familiarizado com o sistema da corporação e de controles internos. Também deve supervisionar o trabalho da auditoria interna, incluindo a revisão dos relatórios apresentados pela equipe de auditoria interna e rever a nomeação e a substituição do executivo sênior de auditoria interna. O comitê de auditoria deve ter reuniões frequentes e suficientes para permitir o acompanhamento adequado dos relatórios anuais e trimestrais. Para muitas empresas, isso significa quatro ou mais reuniões por ano.

$\mathrm{Na}$ França, a proporção de conselheiros independentes sobre o comitê de auditoria deve representar dois terços e o comitê não deve incluir qualquer funcionário da empresa. Os membros do comitê de auditoria devem ter conhecimento em finanças ou contabilidade. A duração do mandato é estabelecida em seis anos. As principais funções são: rever as contas e assegurar a relevância e a consistência dos métodos contábeis utilizados, além de garantir que os procedimentos internos para a coleta e análise de informações sejam seguros.

$\mathrm{Na}$ Holanda, pelo menos um membro do comitê de auditoria deve possuir expertise financeira, na acepção das melhores práticas e não deve ser presidido pelo presidente do conselho fiscal ou por um ex-membro do conselho de administração da empresa. O comitê de auditoria deve funcionar como principal contato com o auditor externo.

O comitê de auditoria na Indonésia é presidido por um diretor independente e os membros podem ser diretores e/ou profissionais de fora da empresa, sendo que pelo menos um deve possuir conhecimento em contabilidade. Tem como função auxiliar o conselho de administração para assegurar que os relatórios financeiros sejam apresentados de forma adequada, de acordo com os princípios de contabilidade geralmente aceitos; a estrutura de controle interno seja adequada e eficaz; auditorias internas e externas sejam conduzidas em conformidade com as normas de auditoria aplicáveis; e os resultados das auditorias sejam acompanhados pela gerência da empresa.

$\mathrm{Na}$ Inglaterra, o conselho de administração deve estabelecer um comitê de auditoria com pelo menos três membros; todos devem ser administradores não executivos; e pelo menos um membro do comitê de auditoria deve ter relevante e recente experiência na área financeira. Entre as funções do comitê de auditoria constam: monitorar a integridade das demonstrações contábeis da empresa; rever controles financeiros internos; revisar e monitorar o trabalho do auditor externo, a independência e a objetividade e eficácia do processo de auditoria; desenvolver e implementar política relativa à contratação do auditor externo, tendo em conta as orientações éticas relevantes sobre a prestação de serviços de auditoria; e o relatório anual deverá explicar aos acionistas como o auditor presta os serviços de auditoria.

O comitê de auditoria na Malásia deve possuir no mínimo três membros, a maioria independentes, e todos devem ser administradores não executivos. O conselho deve fornecer ao comitê de auditoria um documento escrito que especifique os seus direitos e deveres. Todos os membros do comitê devem ser alfabetizados financeiramente e pelo menos um deve ser membro de uma associação ou órgão de contabilidade. Além disso, todos os seus membros devem ser capazes de ler, analisar e interpretar as demonstrações contábeis de modo que sejam capazes de cumprir eficazmente as suas funções. As funções do comitê de auditoria devem incluir o seguinte: nomear o auditor externo; discutir com o auditor externo, antes do início da auditoria, a natureza e o âmbito da auditoria; rever as demonstrações trimestrais e anuais da diretoria; rever o programa de auditoria interna e os resultados do processo de auditoria interna; aprovar qualquer nomeação ou cessação de membros da equipe sênior de auditoria interna; considerar todas as transações com partes relacionadas da empresa ou do grupo; e considerar outros temas, conforme definido pela diretoria.

O código de governança corporativa do México menciona que o comitê de auditoria deve reunir-se regularmente com os auditores internos e externos; contribuir para a definição de diretrizes para o controle interno, auditoria interna e avaliar a sua eficácia; coordenar o trabalho dos auditores externos, internos e comissários; analisar e avaliar as operações com partes relacionadas para recomendar ao conselho de administração; e verificar o cumprimento do código de ética empresarial. O código sugere ainda a regra de rotatividade dos revisores das demonstrações contábeis a cada cinco anos. O Consejo Coordinador Empre- 
sarial (http://www.ecgi.org/codes/documents/codigo_de_mejores_practicas_corporativas_2010_es.pdf), na Práctica 15 recomenda ao Conselho de Administração realizar as funções de auditoria e outros por meio de órgãos intermediários; e a Práctica 16 apresenta-se 8 itens relacionados ao órgão de auditoria.

Em Singapura, o código de governança corporativa enfatiza a importância da independência do comitê de auditoria. Subscreve a ideia de que o presidente do comitê deve ser um diretor independente. Os membros do comitê devem ser devidamente qualificados para aumentar a confiança dos membros e a independência no tratamento do comitê com a administração. Pelo menos dois membros devem possuir conhecimento em contabilidade ou estar relacionados com competências de gestão financeira. O comitê considera que a exigência de pelo menos dois membros com a competência necessária ou a experiência reforçaria a objetividade da opinião do comitê de auditoria e melhoria a eficácia do conselho de administração. O comitê compartilha também a responsabilidade da administração em manter um bom sistema de controle interno.

\subsection{Comparativo da Caracterização do Comitê de Auditoria no Brasil e Outros Países}

Com base na descrição apresentada a respeito dos comitês de auditoria dos diversos países, pode-se fazer um comparativo das semelhanças e diferenças existentes entre o que é proposto no código de governança corporativa do Brasil pelo IBGC (2009b) em relação aos demais países em análise. A Figura 2 aponta as semelhanças identificadas em relação à composição, mandato, qualificação e atribuições do comitê de auditoria, comparado com o que é proposto pelo código de governança corporativa no Brasil.

\begin{tabular}{|c|c|c|c|c|c|c|c|c|c|c|c|c|c|c|c|c|c|}
\hline \multicolumn{2}{|c|}{ Brasil } & 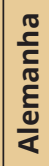 & 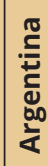 & $\begin{array}{l}\dot{0} \\
\frac{\pi}{0} \\
\frac{\sqrt{0}}{20} \\
\frac{1}{\alpha}\end{array}$ & $\frac{.0}{\frac{\pi}{2}}$ & $\begin{array}{l}\frac{\pi}{0} \\
\frac{1}{0} \\
\frac{5}{0} \\
ن\end{array}$ & $\stackrel{\text { 它 }}{\underline{U}}$ & 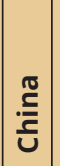 & 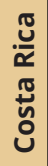 & $\S_{\mathrm{u}}$ & 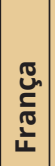 & $\begin{array}{l}\frac{\pi}{0} \\
\frac{c}{\pi} \\
\frac{0}{0} \\
\text { 은 }\end{array}$ & 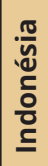 & 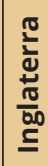 & $\begin{array}{l}\frac{\pi}{\sqrt{n}} \\
\frac{\sqrt{0}}{\pi} \\
\sum\end{array}$ & & 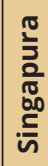 \\
\hline 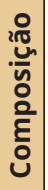 & $\begin{array}{l}\text { Composto de no mínimo três membros do conselho } \\
\text { de administração preferencialmente independentes. }\end{array}$ & & $x$ & $x$ & & $x$ & & & & $x$ & & & & $x$ & $x$ & & \\
\hline \multirow{2}{*}{ 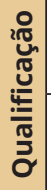 } & $\begin{array}{l}\text { Todos os membros devem ter conhecimentos básicos } \\
\text { de finanças e contabilidade. }\end{array}$ & $x$ & $x$ & & & $x$ & & & & & $x$ & & & & $x$ & & $x$ \\
\hline & $\begin{array}{l}\text { Pelo menos um deverá ter maior experiência na área } \\
\text { contábil, de auditoria e de gestão financeira. }\end{array}$ & $x$ & & $x$ & $x$ & & & & & $x$ & & $x$ & & $x$ & & & \\
\hline 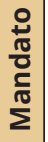 & $\begin{array}{l}\text { Pode ser limitado por meio do rodízio automático e/ } \\
\text { ou pela restrição do número de comitês a que um } \\
\text { membro pode servir em outras empresas. }\end{array}$ & & & & & & & & & & & & & & & & \\
\hline \multirow{5}{*}{ 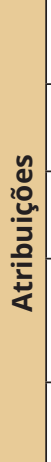 } & $\begin{array}{l}\text { Analisar as demonstrações contábeis e que a auditoria } \\
\text { interna desempenhe a contento o seu papel }\end{array}$ & & $x$ & $x$ & $x$ & & $x$ & $x$ & $x$ & $x$ & $x$ & & $x$ & $x$ & $x$ & & \\
\hline & $\begin{array}{l}\text { Promover a supervisão e a responsabilização da área } \\
\text { financeira }\end{array}$ & & & & & & & & $x$ & $x$ & & & & $x$ & & & \\
\hline & $\begin{array}{l}\text { Garantir que a diretoria desenvolva controles internos } \\
\text { confiáveis }\end{array}$ & & $x$ & & $x$ & & & $x$ & $x$ & $x$ & & & $x$ & & & $x$ & $x$ \\
\hline & $\begin{array}{l}\text { Os auditores independentes devem avaliar, por meio } \\
\text { de sua própria revisão, as práticas da diretoria e da } \\
\text { auditoria interna. }\end{array}$ & & $x$ & & & $x$ & & & & & $x$ & & & & & & \\
\hline & $\begin{array}{l}\text { Zelar pelo cumprimento do código de conduta da } \\
\text { organização. }\end{array}$ & & $x$ & & & & & & & & & & & & & $x$ & \\
\hline
\end{tabular}

Figura 2. Semelhanças entre os comitês de auditoria de outros países em relação ao Brasil Fonte: dados da pesquisa. 
Na Figura 2, observa-se que há várias semelhanças na caracterização do comitê de auditoria no código de governança corporativa dos países analisados em relação ao que é proposto pelo Instituto Brasileiro de Governança Corporativa. No entanto, destaca-se a análise das demonstrações contábeis pelo comitê de auditoria, que é o quesito predominante em quase todos os países que compõem a amostra do estudo.

As características relativas à composição, qualificação e atribuições do comitê de auditoria apresentam mais semelhanças com o que é proposto pelo código brasileiro de governança corporativa. Porém, em relação ao tempo de mandato, poucos são os códigos que fazem menção a respeito e, mesmo nos que indicaram o tempo, não se constataram semelhanças. Nota-se pelo exposto anteriormente que os códigos, muitas vezes, expressam suas atribuições de maneira diferente do que é exposto pelo código brasileiro de governança corporativa, mas a análise das demonstrações contábeis é destacada na maioria dos países.

Em relação às diferenças propostas na caracterização do comitê de auditoria pelos países em estudo, na Figura 3 faz-se uma comparação ao que é proposto pelo código brasileiro de governança corporativa.

\begin{tabular}{|c|c|c|c|c|c|c|c|c|c|c|c|c|c|c|c|c|c|}
\hline \multicolumn{2}{|c|}{ Brasil } & 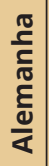 & 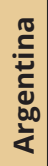 & $\begin{array}{l}\text { v } \\
\frac{\pi}{0} \\
\frac{10}{\sqrt{0}} \\
\frac{2}{\alpha}\end{array}$ & $\begin{array}{l}\frac{\pi}{2} \\
\frac{\operatorname{n}}{3} \\
\frac{2}{2}\end{array}$ & $\begin{array}{l}\frac{\pi}{0} \\
\mathbb{0} \\
\frac{1}{0} \\
ن\end{array}$ & $\frac{0}{\frac{1}{U}}$ & 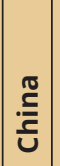 & 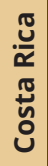 & $\coprod_{\mathrm{u}}$ & 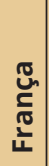 & $\begin{array}{l}\frac{\pi}{0} \\
\frac{\mathrm{C}}{\mathrm{T}} \\
\frac{\mathrm{T}}{0} \\
\text { 우 }\end{array}$ & 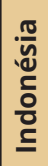 & 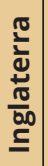 & $\begin{array}{l}\frac{\pi}{n} \\
\frac{\sqrt{0}}{\frac{10}{\pi}} \\
\sum\end{array}$ & $\begin{array}{l}\stackrel{0}{x} \\
\underset{x}{\mathbb{U}}\end{array}$ & 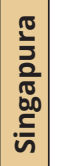 \\
\hline 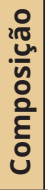 & $\begin{array}{l}\text { Deve ser composto no mínimo por três membros } \\
\text { do conselho de administração, preferencialmente } \\
\text { independentes }\end{array}$ & $x$ & & & & & & & & & $x$ & $x$ & $x$ & & & & \\
\hline \multirow{2}{*}{ 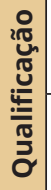 } & $\begin{array}{l}\text { Todos os membros devem ter conhecimentos básicos } \\
\text { de finanças e contabilidade }\end{array}$ & & & & & & & & & & & & & & & & \\
\hline & $\begin{array}{l}\text { Pelo menos um deverá ter maior experiência na área } \\
\text { contábil, de auditoria e de gestão financeira. }\end{array}$ & & & & & & & & & & & $x$ & & & & & $x$ \\
\hline 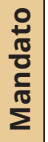 & $\begin{array}{l}\text { Pode ser limitado por meio do rodízio automático e/ } \\
\text { ou pela restrição do número de comitês a que um } \\
\text { membro pode servir em outras empresas. }\end{array}$ & & & & & & & & & & $x$ & & & & & & \\
\hline \multirow{5}{*}{ 造 } & $\begin{array}{l}\text { Analisar as demonstrações contábeis e que a auditoria } \\
\text { interna desempenhe a contento o seu papel }\end{array}$ & & & & & & & & & & & & & & & & \\
\hline & $\begin{array}{l}\text { Promover a supervisão e a responsabilização da área } \\
\text { financeira }\end{array}$ & & & & & & & & & & & & & & & & \\
\hline & $\begin{array}{l}\text { Garantir que a diretoria desenvolva controles internos } \\
\text { confiáveis }\end{array}$ & & & & & & & & & & & & & & & & \\
\hline & $\begin{array}{l}\text { Assegurar que os auditores independentes avaliem, } \\
\text { por meio de sua própria revisão, as práticas da } \\
\text { diretoria e da auditoria interna. }\end{array}$ & & & & & & & & & & & & & & & & \\
\hline & $\begin{array}{l}\text { Deve zelar pelo cumprimento do código de conduta da } \\
\text { organização. }\end{array}$ & & & & & & & & & & & & & & & & \\
\hline
\end{tabular}

Figura 3. Diferenças entre os comitês de auditoria de outros países em relação ao Brasil Fonte: dados da pesquisa.

Nota-se na Figura 3 que poucas são as diferenças constatadas. Na composição do comitê de auditoria, destaca-se que na Alemanha o presidente do comitê não deve ser um ex-membro do conselho administrativo da companhia, cuja nomeação tenha acabado a menos de dois anos atrás. Na França, a proporção de conselheiros independentes do comitê deve ser de dois terços e não pode incluir funcionários da empresa. Na Holanda, o comitê não deve ser presidido pelo presidente do conselho fiscal ou por um ex-membro do conselho de administração da empresa. Na Indonésia, o comitê é presidido por um membro independente e os membros podem ser profissionais de fora da empresa. 
Em relação à qualificação, na Holanda pelo menos um membro do comitê de auditoria deve ser um especialista financeiro, na acepção das melhores práticas. O código Holanda propõe ainda para o comitê de auditoria a política da empresa no planejamento tributário e as aplicações de tecnologia da informação e comunicação (TI). Em Singapura, ao contrário do que é proposto pelo código brasileiro, deve possuir pelo menos dois membros com conhecimento em contabilidade ou com competência de gestão financeira.

No que concerne ao mandato do comitê de auditoria, uma principal diferença pode ser apontada no código de governança corporativa da França, em que o tempo de mandato é estabelecido em 6 anos, e sua natureza renovável, para garantir a sua independência. Ressalta-se que poucos códigos de governança dos analisados mencionaram a respeito, talvez isso justifique as poucas diferenças identificadas nessa característica.

No geral, existem poucas diferenças entre o que é proposto no código de governança corporativa dos outros países analisados em relação ao Brasil. Constataram-se diferenças apenas em relação ao tempo de mandato e as qualificações exigidas em outros países. Em relação ao tempo de mandato, o país que faz menção informa outro período, porém os demais países não comentam a respeito disso em seus códigos.

Alguns códigos de governança corporativa também apontam como atribuição do comitê de auditoria a apresentação de relatórios periódicos ao conselho sobre as medidas tomadas e problemas discutidos em reuniões. Essas reuniões devem acontecer com certa frequência, conforme explicitado no código de alguns países. Também é muito comentado a respeito da contratação da empresa de auditoria externa e sobre a fiscalização do seu trabalho, porém o código brasileiro de governança corporativa não comenta em relação a isso, apenas aborda sobre assuntos que devem ser tratados com os auditores independentes.

\subsection{Caracterização do Comitê de Auditoria em Empresas de Santa Catarina}

De modo complementar, com vistas a cotejar a teoria com a empiria, neste tópico descrevem-se as características dos comitês de auditoria das empresas catarinenses pesquisadas. Os dados foram obtidos do site da Bovespa, em que as empresas disponibilizam informações sobre as práticas adotadas de governança corporativa, além de seus relatórios contábeis.

Como algumas empresas possuem o conselho fiscal, com características por vezes equivalentes ao comitê de auditoria, optou-se por fazer tal análise verificando se as empresas possuem o comitê de auditoria e ou o conselho fiscal. As empresas que possuem o comitê de auditoria ou o conselho fiscal atuante são as seguintes: BRF - Brasil Foods S.A.; Centrais Elétricas de Santa Catarina S.A - CELESC; Cremer S.A.; Döhler S.A.; Marisol S.A.; Renar Maçãs S.A.; TEKA - Tecelagem Kuehnrich S.A.; Tractebel Energia S.A.; e WEG S.A.

Duas das empresas pesquisadas, a Buettner S.A. e a Eletro Aço Altona S.A., não informaram em seu site se possuem o comitê de auditoria ou o conselho fiscal atuante na empresa, mas como ambas são companhias abertas, de acordo com o Capítulo XIII da Lei n. ${ }^{\circ}$ 6.404/76 deve haver no mínimo o Conselho Fiscal. A única empresa entre as pesquisadas que informa possuir tanto o comitê de auditoria como o conselho fiscal é a Souza Cruz S.A.

Em relação à atuação do comitê de auditoria e do conselho fiscal nas empresas pesquisadas, a análise pautou-se nas categorias composição, qualificação, mandato e atribuições, conforme exposto na Figura 4. 


\begin{tabular}{|c|c|c|c|c|}
\hline \multirow{2}{*}{ Empresa } & \multicolumn{4}{|c|}{ Comitê de Auditoria/Conselho Fiscal } \\
\hline & Composição & Qualificação & Mandato & Atribuições \\
\hline $\begin{array}{l}\text { BRF - Brasil } \\
\text { Foods S.A }\end{array}$ & $\begin{array}{l}\text { Comitê de auditoria } \\
\text { constituído por } \\
\text { três membros } \\
\text { independentes. }\end{array}$ & $\begin{array}{l}\text { Um de seus } \\
\text { membros deve } \\
\text { ser especialista } \\
\text { financeiro. }\end{array}$ & Não faz referência & $\begin{array}{l}\text { Reúne-se mensalmente e, } \\
\text { quando necessário, pode } \\
\text { deliberar em conjunto com o } \\
\text { conselho de administração. }\end{array}$ \\
\hline Buettner S.A & Não faz referência & Não faz referência & Não faz referência & Não faz referência \\
\hline CELESC & $\begin{array}{l}\text { Conselheiros, } \\
\text { diretores e } \\
\text { empregados. }\end{array}$ & Não faz referência & Não faz referência & $\begin{array}{l}\text { Cumprimento na apuração } \\
\text { de informações, além de dar } \\
\text { subsídios à tomada de decisão. }\end{array}$ \\
\hline Cremer S.A & Não faz referência & Não faz referência & $\begin{array}{l}\text { Conselho fiscal, } \\
\text { eleito em assembleia } \\
\text { geral de acionistas } \\
\text { com mandato de um } \\
\text { ano, podendo ser } \\
\text { reeleito. O mandato } \\
\text { expira na assembleia } \\
\text { geral ordinária } \\
\text { subsequente. }\end{array}$ & $\begin{array}{l}\text { Fiscalizar administradores, } \\
\text { opinar sobre propostas a serem } \\
\text { submetidas à assembleia geral, } \\
\text { examinar as demonstrações } \\
\text { contábeis da companhia e } \\
\text { denunciar aos órgãos de } \\
\text { administração e à assembleia } \\
\text { geral os erros, fraudes ou crimes } \\
\text { de que tiverem conhecimento. }\end{array}$ \\
\hline Döhler S.A & Não faz referência & Não faz referência & Não faz referência & Não faz referência \\
\hline Altona S.A & Não faz referência & Não faz referência & Não faz referência & Não faz referência \\
\hline Marisol S.A & $\begin{array}{l}\text { Conselho fiscal, } \\
\text { com representantes } \\
\text { de acionistas } \\
\text { minoritários e } \\
\text { preferencialistas. }\end{array}$ & Não faz referência & Não faz referência & Não faz referência \\
\hline Renar Maçãs S.A & Não faz referência & Não faz referência & Não faz referência & Não faz referência \\
\hline Souza Cruz S.A & $\begin{array}{l}\text { Comitê de auditoria, } \\
\text { com quatro membros } \\
\text { externos apontados } \\
\text { pelo conselho de } \\
\text { administração. }\end{array}$ & Não faz referência & Não faz referência & $\begin{array}{l}\text { O comitê se reúne três vezes } \\
\text { por ano e discute temas ligados } \\
\text { a todos os riscos do negócio, } \\
\text { como de crédito, cambial e de } \\
\text { mercado. }\end{array}$ \\
\hline $\begin{array}{l}\text { TEKA - } \\
\text { Tecelagem } \\
\text { Kuehnrich S.A }\end{array}$ & $\begin{array}{l}\text { O conselho } \\
\text { fiscal possui três } \\
\text { membros, com um } \\
\text { representante dos } \\
\text { preferencialistas. }\end{array}$ & Não faz referência & Não faz referência & $\begin{array}{l}\text { Reúne-se mensalmente para } \\
\text { a avaliação das informações } \\
\text { contábeis, atribuições na forma } \\
\text { da lei e contato com a auditoria } \\
\text { externa e interna. }\end{array}$ \\
\hline $\begin{array}{l}\text { Tractebel } \\
\text { Energia S.A }\end{array}$ & $\begin{array}{l}\text { Três membros no } \\
\text { conselho fiscal, e } \\
\text { um deles indicado } \\
\text { pelos acionistas } \\
\text { minoritários. }\end{array}$ & Não faz referência & $\begin{array}{l}\text { Eleitos pelo conselho } \\
\text { de administração, } \\
\text { com mandato de três } \\
\text { anos e permissão a } \\
\text { reeleição. }\end{array}$ & Não faz referência \\
\hline WEG S.A & $\begin{array}{l}\text { Composto de até } \\
\text { cinco membros } \\
\text { efetivos e igual } \\
\text { número de suplentes. }\end{array}$ & Não faz referência & Não faz referência & Não faz referência \\
\hline
\end{tabular}

Figura 4. Atuação dos comitês de auditoria das empresas catarinenses pesquisadas

Fonte: dados da pesquisa.

Verifica-se na Figura 4 que algumas empresas não reportam a composição de seu comitê de auditoria. Porém, nas que comentam observa-se que seguem o proposto pelo código brasileiro de governança corporativa, que o mínimo deve ser de 3 membros. A Celesc e a Marisol apenas mencionam que deve ser formado por conselheiros, diretores e empregados, e com representantes de acionistas minoritários e preferencialistas, respectivamente. 
Quanto à qualificação, apenas a empresa BRF - Brasil Foods S.A. aponta que pelo menos um dos membros do conselho fiscal deve possuir comprovados conhecimentos nas áreas de contabilidade, auditoria e financeira, que o caracterize como um especialista financeiro, conforme definido na Sarbanes-Oxley Act dos Estados Unidos. Talvez essa observação esteja associada ao fato de esta empresa possuir American Depositary Receipt $(A D R)$ e, portanto, está sujeita ao cumprimento dessa lei norte-americana no Brasil.

Vale ressaltar que o conselho fiscal da BRF - Brasil Foods S.A., além de exercer as atividades previstas na legislação societária brasileira, Lei n. ${ }^{\circ} 6.404 / 76$, realiza as funções do comitê de auditoria, prevista na lei Sarbanes-Oxley (SOX) e nas regras da Securities and Exchange Commission (SEC), dos Estados Unidos (EUA). A SEC reconhece que, devido à legislação local para emissores estrangeiros privados, algumas funções do comitê de auditoria podem estar subordinadas às leis locais e a outros órgãos internos.

Observa-se no comitê de auditoria ou no conselho fiscal das empresas pesquisadas que pelo menos um de seus membros possui formação em Ciências Contábeis, porém em sua maioria são compostos por membros com formação em Direito. As empresas não mencionaram no relatório da administração ou em seu site as qualificações exigidas para se tornar um membro do comitê de auditoria. Porém, cinco empresas não trazem nenhuma informação a respeito da composição do seu comitê de auditoria e as qualificações exigidas.

Em relação ao tempo de mandato, apenas a Cremer S.A. e a Tractebel Energia S.A. divulgam o tempo de mandato de seu comitê de auditoria, que são, respectivamente, de 1 ano e 3 anos. Na empresa BRF - Brasil Foods S.A, é informado que o mandato do conselho de administração é de 2 anos, sendo permitida a reeleição, porém não faz menção em relação ao tempo do comitê de auditoria.

No que concerne ao tempo de mandato, a Resolução CMN n. ${ }^{\circ}$ 3.198, de 27 de maio de 2004, informa que o máximo deve ser de cinco anos para as instituições com ações negociadas em bolsa de valores e sem mandato fixo para aquelas de capital fechado. O IBGC (2009b) orienta que os membros devem ser independentes, não atuar em outra área da empresa e deve existir um rodízio em relação a sua atuação no comitê. Assim, das empresas que informaram o tempo de mandato dos membros do comitê de auditoria, elas estão em conformidade com o estabelecido pelas normas brasileiras e pelo IBGC.

Entre as empresas que informaram as atribuições dos membros do comitê de auditoria, observa-se que seguem o que é proposto pelo código brasileiro de governança corporativa. Reportaram que o comitê deve atuar junto com o conselho de administração em suas atividades, participando de reuniões, e participar nas tomadas de decisões, como também na análise de riscos da empresa. Todavia, seis empresas não informaram no site da Bovespa, em seu próprio site ou no relatório da administração, as atribuições dos membros do comitê de auditoria ou do conselho fiscal.

Das empresas analisadas, a BRF - Brasil Foods S.A., a Cremer S.A., a Tratctebel Energia S.A. e a WEG S.A. estão no Novo Mercado da Bovespa, e a empresa Centrais Elétrica de Santa Catarina S.A. CELESC está no Nível 2. As demais empresas não informam no site da Bovespa em qual mercado se encontram atualmente.

A Bovespa (2010, p. 3) caracteriza o novo mercado como sendo "direcionado principalmente à listagem de empresas que venham a abrir capital". Tanto o nível 2 como o Novo Mercado tem o compromisso de divulgar suas demonstrações contábeis de acordo com os padrões United States Generally Accepted Accounting Principles (US GAAP) ou International Financial Reporting Standards (IFRS) (Bovespa, 2010). E o conselho de administração de ambos deve ser composto por, no mínimo, cinco membros com mandato unificado de, no máximo, dois anos.

Depreende-se que as empresas listadas em algum nível de governança corporativa no site da Bovespa disponibilizam a maioria das informações sobre a atuação do seu conselho fiscal. Chama atenção a Souza Cruz S.A., que não está listada em nenhum nível de governança corporativa da Bovespa, mas apresenta as informações sobre seu comitê de auditoria, o que pode decorrer do fato de ser uma multinacional e ter seu comitê de auditoria atuante já por vários anos. Nota-se também que as empresas Buettner S.A. e Eletro Aço Altona S.A. não reportam nenhuma informação, nem mesmo informam se possuem implantado o comitê de auditoria ou o conselho fiscal. 


\section{Conclusões}

O estudo teve por objetivo comparar a caracterização proposta para os comitês de auditoria no Código de Governança Corporativa do Brasil e de outros países. Para tal, foi realizada pesquisa em 17 países que possuem código de governança corporativa publicado em algum site, e que fazem menção às atribuições do comitê de auditoria. De modo complementar, para analisar a implementação do que é proposto ao comitê de auditoria no Brasil pelo IBGC, investigaram-se empresas catarinenses que possuem ações negociadas na Bovespa.

$\mathrm{Na}$ análise do conteúdo do código de governança corporativa do Brasil e de outros países, verificou-se que todos possuem o mesmo objetivo, que é evitar o conflito de interesses, agregar valor às empresas, conferir transparência às demonstrações contábeis e assim ampliar o número de investidores e o volume de investimentos. A maioria dos códigos já prevê a adoção das normas internacionais de contabilidade, o que coaduna com a padronização dos procedimentos contábeis necessários às empresas com ações negociadas em bolsas de valores de diferentes países.

Em relação à caracterização do comitê de auditoria, quanto a sua composição, qualificação dos membros, mandato e atribuições, verificou-se que há poucas diferenças entre o proposto no código de governança corporativa do Brasil em comparação ao dos outros países pesquisados. Nas atribuições do comitê de auditoria, destaca-se "analisar as demonstrações contábeis", que é contemplado em mais de dois terços dos códigos de governança corporativa analisados. Essa atribuição justifica a exigência de um dos membros possuir conhecimento comprovado de contabilidade ou de finanças.

No outro extremo está a omissão dos códigos sobre o tempo de mandato do comitê de auditoria nas empresas. A ausência de declaração de prazos de mandato pode representar certa flexibilidade às empresas. De outro lado, isso pode induzir as empresas a não buscar a renovação dos membros do comitê, o que, possivelmente, prejudica a isenção necessária no desempenho de suas funções, devido a laços que se criam ao longo do tempo. O estabelecimento de parâmetros de período de permanência do comitê de auditoria também é interessante para fins de comparação das suas características em diferentes empresas.

De modo geral, na análise das semelhanças e diferenças da caracterização proposta para o comitê de auditoria desses países, verificou-se que existe um alinhamento com o que é proposto no código de governança corporativa do Brasil. Um fator que pode ter motivado essa padronização entre os códigos foi a edição do OECD Principles of Corporate Governance, da Organisation for Economic Co-Operation and Development (OECD, 2004), traduzido para o português como Organização para a Cooperação e o Desenvolvimento Econômico (OCDE), que foi um marco na governança corporativa e porque motivou diversos países a editar seu código de governança corporativa.

Em relação às características do comitê de auditoria em empresas catarinenses com ações negociadas na Bovespa, verificou-se que atualmente as empresas têm adotado o conselho fiscal em vez do comitê de auditoria. Apenas uma das 12 empresas analisadas possui ambos, o comitê de auditoria e o conselho fiscal. Isso talvez se dá pelo fato que a Securities and Exchange Commission (SEC, 2000) permitiu que as companhias brasileiras com ações negociadas nas Bolsas de Valores do Estados Unidos pudessem escolher entre adotar o comitê de auditoria ou o conselho fiscal.

Porém, o Código Brasileiro de Governança Corporativa informa que o comitê de auditoria não deve ser substituído pelo conselho fiscal; o que pode acontecer é possuir além do comitê de auditoria, o conselho fiscal, mas isso vai depender do entendimento dos acionistas, em implanta-lo ou não. Observou-se também nestas empresas que pouco reportam sobre as qualificações dos seus membros, composição e o tempo de mandato. Apenas apresentam atribuições que são exigidas internamente para os membros da empresa, ou até mesmo o nome e a formação dos membros do conselho fiscal ou do comitê de auditoria.

Conclui-se que, apesar das semelhanças na caracterização dos comitês de auditoria identificada nos códigos de governança corporativa dos diversos países pesquisados, pesquisas adicionais são necessárias para criar um padrão que os órgãos reguladores possam propor para implementação nas empresas. Essa proposição encontra sustentação na investigação de companhias abertas que possuem o conselho fiscal 
em detrimento do comitê de auditoria, embora o IBGC (2009b) recomende a adoção do comitê de auditoria para todas as empresas, e não apenas as que possuem ações negociadas em bolsa de valores.

Considerando-se as limitações da pesquisa, recomenda-se ampliar a análise da caracterização do comitê de auditoria em códigos de governança corporativa de outros países. Recomenda-se também reaplicar o estudo em empresas de outros estados do Brasil e até mesmo de outros países, a fim de constatar semelhanças e divergências nos resultados. Outra sugestão é realizar o estudo em empresas que não possuem ações negociadas em bolsa de valores, a fim de verificar se possuem o comitê de auditoria. Seria interessante também verificar as motivações das empresas para substituir o comitê de auditoria pelo conselho fiscal, conforme constatado nesta pesquisa em uma pequena amostra de empresas.

\section{Referências}

Blue Ribbon Committee. (1999). Reporting and recommendations of the Blue Ribbon Committee on improving the effectiveness of corporate audit committee. New York: New York Exchange and National Association of Securities Dealers.

Lei $n^{\circ}$. 6.404, de 15 de dezembro de 1976. Dispõe sobre as Sociedades por Ações. Recuperado em 03 janeiro, 2013 de http://www.portaldecontabilidade.com.br/legislacao/lei6404_1976.htm.

Bronson, S.N., Carcello, J.V., Hollingsworth, C.W., \& Neal, T.L. (2009) Are fully independent audit committees really necessary? Journal of Accounting and Public Policy, 28(4), 265-280.

Carcello, J.V., Hermanson, D.R., \& Neal, T.L. (2002). Disclosures in audit committee charters and reports. Accounting Horizons, 16(4), 291-304.

Carcello, J.V., \& Neal, T.L. (2000). Audit Committee composition and auditor reporting. The Accounting Review, 75(4), 453-467.

Chan, A., Liu, G. \& Sun, J. (2012). Independent audit committee members' board tenure and audit fees. Paper 22. Canadá: Odette School of Business Publications.

Chatterjee, D. (2011). Audit committee observation/recommendations versus prectices as a compliance of corporate governance in Índia. DSLU Business \& Economics Review, 20(2), 67-78.

Cipullo, E. (2006). Como implementar um comitê de auditoria: sua importância na governança corporativa. São Paulo: Trevisan.

Conselho Monetário Nacional (CMN). Resolução $n^{\circ} 3.198$, de 27 de maio de 2004, altera e consolida a regulamentação relativa à prestação de serviços de auditoria independente para as instituições financeiras, demais instituições autorizadas a funcionar pelo BACEN e para as câmaras e prestadores de serviços de compensação e de liquidação. Recuperado em 03 janeiro, 2013 de https://www3.bcb. gov.br/normativo/detalharNormativo.do? $\mathrm{N}=104080599$ \&method=detalharNormativo.

DeZoort, F.T., Hermanson, D.R., Archmbeault, D.S., \& Scoot, A.R. (2002). Audit committee effectiveness: a synthesis of the empirical audit committee literature. Journal of Accounting Literature, 21(1), 38-75.

DeZoort, F.T., \& Salterio, S.E. (2001). The effects of corporate governance experience and financial-reporting and audit knowledge on audit committee members' judgments. Auditing, 20(31), 18-49.

Engel, E., Hayes, R.M., \& Wang, X. (2007). The Sarbanes-Oxley Act and firms' going-private decisions. Journal of Accounting and Economics, 44 (1-2), 116-145.

European Corporate Governance Institute (ECGI). Index of codes. Recuperado em 03 janeiro, 2013 de http://www.ecgi.org/codes/all_codes.php. 
Furuta, F. (2010). A relação das características das empresas com a adoção do Comitê de Auditoria X Conselho Fiscal adaptado. 2010. Tese (Doutorado em Ciências Contábeis) -Universidade de São Paulo, São Paulo, SP, Brasil.

Gil, A.C. (2002). Como elaborar projetos de pesquisa. (4. ed.) São Paulo: Atlas.

Guerra, S. (2009). Os papéis do Conselho de Administração em empresas listadas no Brasil. Dissertação (Mestrado em Administração) - Universidade de São Paulo, São Paulo, SP, Brasil.

Instituto Brasileiro de Governança Corporativa (IBGC). (2007). Código das melhores práticas de governança corporativa. (4 reimpressão) São Paulo, SP: IBGC.

Instituto Brasileiro de Governança Corporativa (IBGC). (2009). Guia de orientação para melhores práticas de comitês de auditoria. São Paulo: IBGC.

Lakatos, E.M., \& Marconi, M.A. (2001). Fundamentos de metodologia científica. (4. ed.) São Paulo: Atlas.

McDaniel, L., Martin, R.D., Maines, L.A., \& Peecher, M.E. (2002). Evaluating financial reporting quality: the effects of financial expertise vs financial literancy. The Accounting Review, 77(Suplement), 139-167.

Mustafa, S., \& Youssef, N.B. (2010). Audit committee financial expertise and misappropriation of assets. Managerial Auditing Journal. 25(3), 208-225.

Niyama, J.K. (2005). Contabilidade internacional. São Paulo: Atlas.

Organisation for Economic Co-operation and Development (OECD). (2004). OECD Principles of Corporate Governance. Recuperado em 03 janeiro, 2013 de http://www.oecd.org/daf/corporateaffairs/ corporategovernanceprinciples/31557724.pdf.

PricewaterhouseCoopers. (2007). Comitês de Auditoria no Brasil: melhores práticas de governança corporativa. (2. ed.) Recuperado em 12 setembro, 2010 de www.origin-pwc.pwc.com/br/pt/publicacoes/ assets/melhores-praticas-07.pdf.

Public Company Accounting Oversight Board (PCAOB). (2013). About PCAOB. Recuperado em 10 maio, $2013 \mathrm{de} \mathrm{http://pcaobus.org/About/Pages/default.aspx.}$

Richardson, R.J., \& Peres, J.A.S. (1989). Pesquisa social: métodos e técnicas. (2. ed.) São Paulo: Atlas.

Securities and Exchange Commission (SEC). (2000). Audit committee disclosure. Recuperado em 03 janeiro, $2013 \mathrm{de} \mathrm{http://www.sec.gov/rules/final/34-42266.htm.}$

Sharma, V., Naiker, V., \& Lee, B. (2009). Determinants of audit committee meeting frequency: evidence from voluntary governance system. Accounting Horizons. 23(3), 245-263.

Silva, E.C. (2006). Governança corporativa nas empresas: guia prático de orientação para acionistas e conselho de administração. São Paulo: Atlas.

United States of America. The Sarbanes-Oxley Act. 2002, July. Recuperado em 03 janeiro, 2013 de http:// www.soxlaw.com/index.htm.

Vicknair, D., Hickman, K., \& Carnes, K.C. (1993). A note on audit committee independence: evidence from the NYSE on "grey" area directors. Accounting Horizons, 7(1), 53-57. 